\title{
UV RADIATION ASSISTED PHOTOCATALYTIC TRANSFORMATION OF AZO DYE DIRECT YELLOW-9
}

\author{
Himakshi Verma ${ }^{1}$, Neelakshi Verma ${ }^{2}$, Shiv Ram Saini ${ }^{3}$, R. C. Meena ${ }^{4}$ \\ ${ }^{1}$ Research Scholar, Department of chemistry, JNVU, Jodhpur, Rajasthan, India \\ ${ }^{2}$ Research Scholar, Department of chemistry, JNVU, Jodhpur, Rajasthan, India \\ ${ }^{3}$ Research Scholar, Department of chemistry, JNVU, Jodhpur, Rajasthan, India \\ ${ }^{4}$ Associate professor, Department of chemistry, JNVU, Jodhpur, Rajasthan, India
}

\begin{abstract}
Advanced oxidation process (AOP) is best for treatment of textile industries effluents (waste water). Methylene blue immobilized resin dowex-11; a photocatalyst is used for transformation of azo dyes. The mechanism of the photo transformation depends on the radiation used. Activity of catalyst remains unaffected on continuous use. The process follows pseudo first order kinetics according to Langmuir Hinshelwood model, the value of rate constant $k$ is $1.43 * 10^{-2} \mathrm{~min}^{-1}$ and approximately $94.60 \%$ of the dye was transforms within 160 min of irradiation.
\end{abstract}

Keywords: Transformation, Direct Yellow-9, Methylene blue immobilized resin, Textile effluents; Dowex-11, Photocatalyst.

\section{INTRODUCTION}

Water is a precious commodity. Clean drinking water is a basic human need. Groundwater forms a major source of drinking water in urban as well as rural areas. Water is universal solvent so it has the capability to dissolve nearly all natural compounds. Significance of water as natural agent is not only determined by its availability, but also determined by its physical and chemical properties [1].

Water scarcity is becoming a global concern. Although water covering more than $70 \%$ of the earth's surface, it is commonly viewed by peoples as a limitless resource. This view however, is quickly changing because of the freshwater sources are being depleted at alarming rates. Through the increase of water usage \& pollution, water scarcity is becoming a problem in which population and industrialization play a vital role. During textile fiber processing, dyeing is a fundamental operation which causes the production of more or less colored wastewaters [2]. On this way, use and disposal of wastewater from textile or other industries are important considerations when assessing environmental impact of textiles. Azo dyes, aromatic moieties linked together by azo $(-\mathrm{N}=\mathrm{N}-)$ chromophores, represent the largest class of dyes used in textile processing and other industries. The release of these compounds into the environment is undesirable, not only because of their color, but also because many azo dyes and their breakdown products are toxic and mutagenic to life. These industrial waste discharges in water bodies alter the $\mathrm{pH}$; increase the BOD \& COD [3-5].

Advance Oxidation Processes were based on the generation of very reactive species such as hydroxyl radicals that oxidize a broad range of pollutants quickly and non- selectively [6]. Heterogeneous photocatalysis is one of the most important methods of the new advanced oxidation technologies to be applied to water purification. A newly developed Photocatalyst MBIR Dowex-11 is a cheap, better and has vast potential of transformation of azo dyes [7-12]. Aim of the present work is to seek attention of researchers towards utilization of solar energy for photo decolorization of azo dye pollutants by Photocatalyst.

\section{MATERIALS AND METHODS}

\subsection{Reagent and Chemicals}

Photocatalyst were prepared by following materials Dowex 11 Resin 20-50 mesh (Sisco Chemicals, India Mumbai), methylene blue hydrate for Microscopy (Loba Chemicals India). For immobilization we prepare approximately $\mathrm{M} / 1000$ concentration solution of methylene blue in double distilled water and add Dowex-11 resin in this solution and shake well. After completing immobilization of methylene blue inside the pores of resin, filter prepared resin from solution, wash this resin by double distilled water twice and used it as Photocatalyst. All the process carried out in dark place.

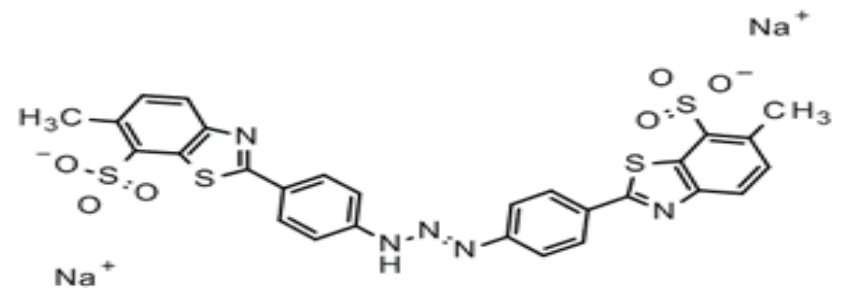

Fig-1 Structure of Dye 
Azo dye Direct Yellow-9 $\left(\mathrm{C}_{28} \mathrm{H}_{19} \mathrm{Na}_{2} \mathrm{~N}_{5} \mathrm{O}_{6} \mathrm{~S}_{4}\right)$; mol. wt.$695.71 \mathrm{gm} / \mathrm{mol}$; wave length- 410nm; (Loba Chemicals, India) is used (Fig-1), also known as Titan Yellow, Clayton Yellow, and Thiazole Yellow G. Direct Yellow-9 is used as a stain and fluorescent indicator in microscopy. It was successfully applied in analytical methods of magnesium determination in serum [13], tissue [14], plant material [15] and rocks [16]. It was also used for estimation of beryllium in waste water [17], commercial amino glycoside antibiotics in serum samples [18], and tetracycline antibiotics in chook serum and human urine samples [19].

\subsection{Analytical Methods}

Photochemical transformation experiments were carried out in glass reactor which containing solution of Azo dye and Photocatalyst. Solution of reactor is continuously stirred by magnetic stirrer during the experiment. The solution is illuminated by halogen lamp (Philips, India) above the reactor which emitted irradiation comparable to visible light. The intensity was measured by photometer (IL1400A). The lamp was surrounded with aluminum reflector in order to avoid loss of irradiation and $\mathrm{pH}$ of the solution was monitored by Fisher Scientific Acumen 50. The mechanism of the photo transformation process under UV-Visible light illumination involves an electron excitation and generation of very active oxygenated species that attack the dye molecules leading to photo transformation.

The change in dye concentration is observed simply by Shimadzu-1600 UV/Visible spectrophotometer at $\lambda_{\max }$. We shuck out $10 \mathrm{ml}$ of solution by pipette at the 10 minute time interval, Filter the catalyst particles and calculate the removal efficiency (X\%) of dye solution by this equation.

$$
\mathrm{X} \%=(\mathrm{Ci}-\mathrm{Ct} / \mathrm{Ci}) \times 100
$$

Where, $\mathrm{Ci}$ and $\mathrm{Ct}$ are optical densities of dye solution at initial time and at time $\mathrm{t}$ respectively.

\subsection{Chemical Reaction of Dye Transformation}

Methylene Blue is a photosensitive dye; when irradiated with light radiations; electronic transition occurs from VB to $\mathrm{CB}$ and through intersystem crossing (ISC) electron reach in to triplet state of Methylene Blue. Intermolecular electronic transition starts between photo catalyst, Methylene Blue dye molecules, water molecules and Direct yellow-9 dye molecules resulting into highly oxidizing agents, holes, hydroxyl radicals and super oxide ions (Fig-2), which transfer azo dye in simple organic compounds. Main factors influencing photo catalytic transformation of azo dye are $\mathrm{pH}$ of the solution, variation in catalyst loading, concentration of dye and light intensity. Methylene Blue becomes excited by absorbing photons of light radiation from ground state to singlet state. Through ISC electron can transfer to triplet state of Methylene Blue. Further intermolecular electronic transition occurs between photo catalyst, Methylene Blue and dye solution and resultant is formation of holes, hydroxyl radicals and super oxide ions which are main oxidative agents in the photo catalytic reaction.

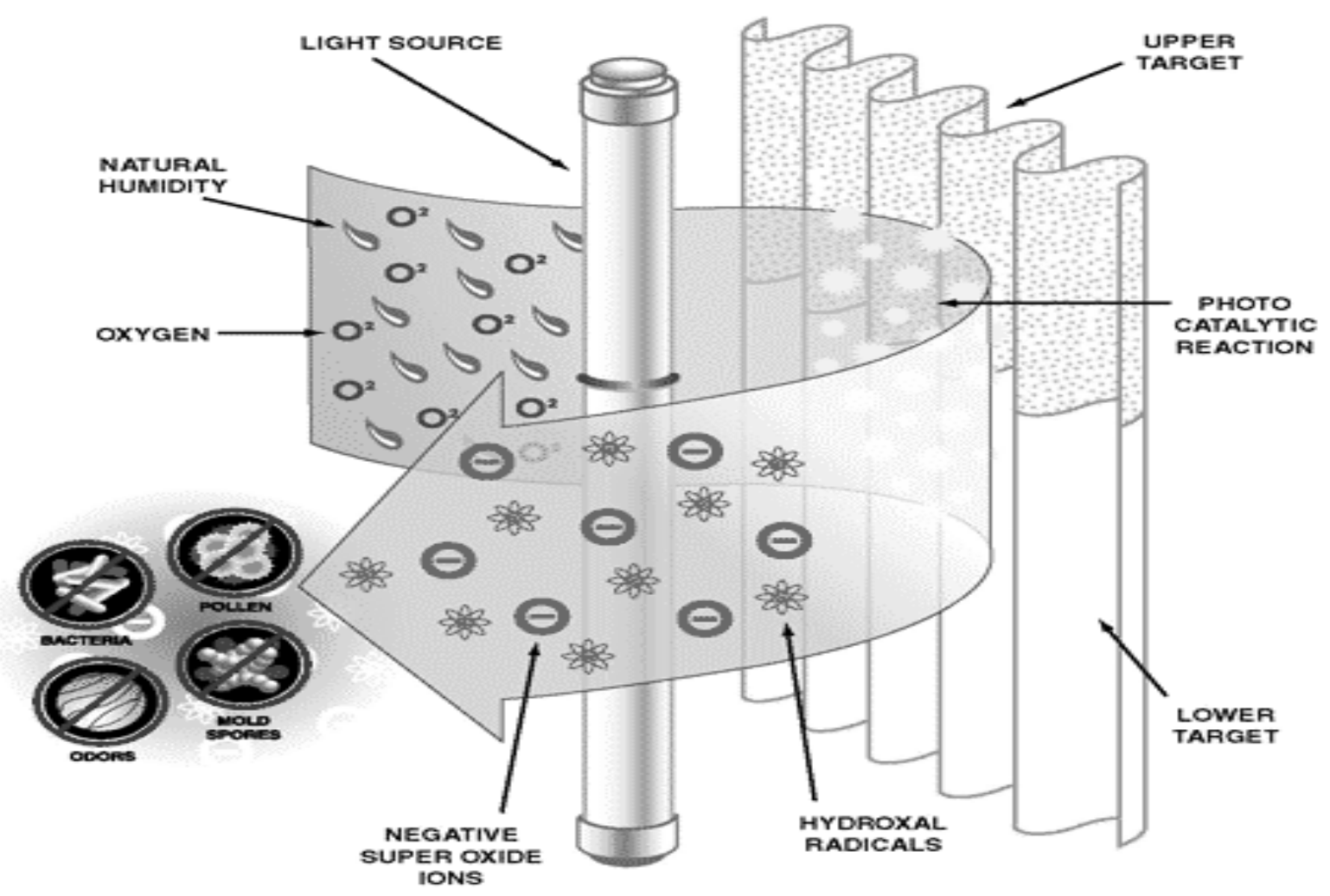

Fig-2 Process of generation of holes, hydroxyl radicals and super oxide ions 


\section{RESULT \& DISCUSSION}

The photocatalytic transformation of Direct yellow-9 was observed at wave length 398-402 $\mathrm{nm}$. The optimum condition was obtained at initial dye concentration $40 \mathrm{mg} / \mathrm{l}$, catalyst loading $2 \mathrm{gm}$, light intensity10.4 mWcm-2, pH 7.5 and temperature $303 \mathrm{~K}$. Photo transformation efficiency of dye at optimum conditions is shown in fig-3.

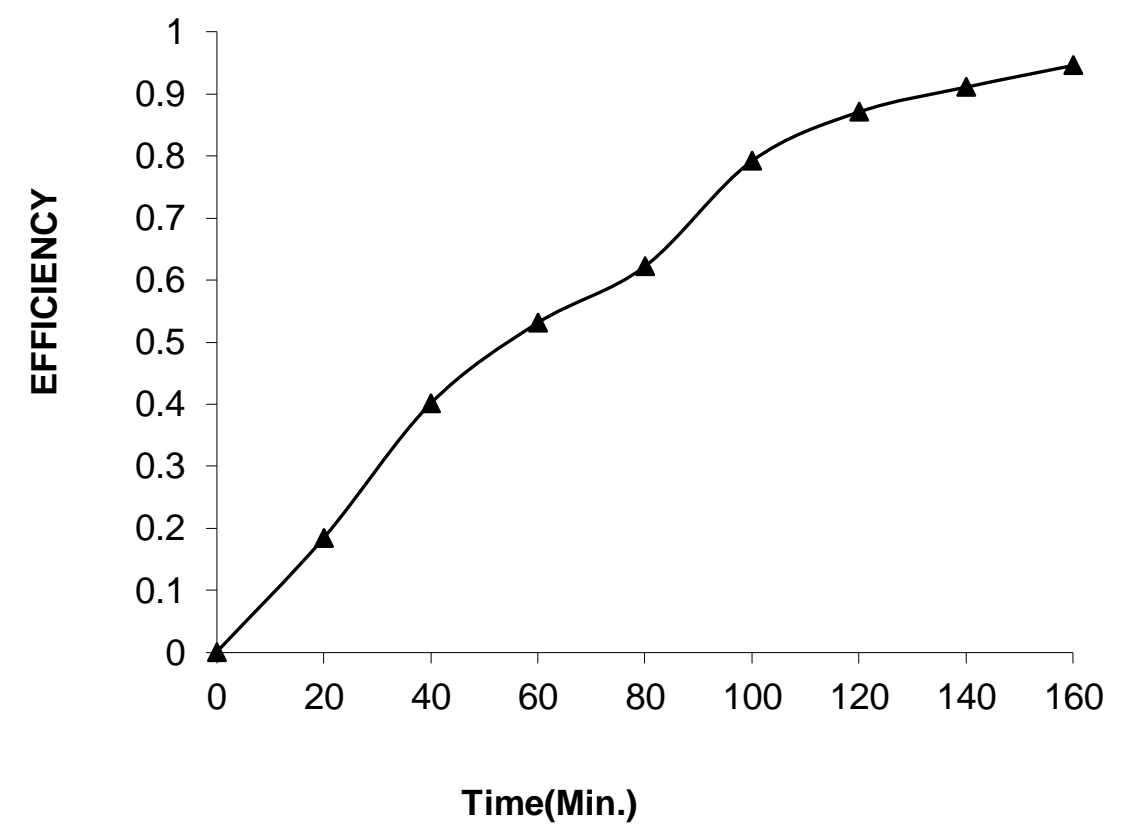

Fig-3 Removal Efficiency of dye

The plot of $1+\log$ O.D. versus exposure time is straight line which indicates that the photocatalytic decolorization of azo dye follows pseudo first order kinetics (fig-4). The rate constant $\mathrm{K}$ for the reaction was determined using expression - rate $=\mathrm{K}$ [azo dye], $\mathrm{K}=2.303 *$ slope. The rate constant of dye is $1.43 * 10^{-2} \mathrm{~min}^{-1}$.

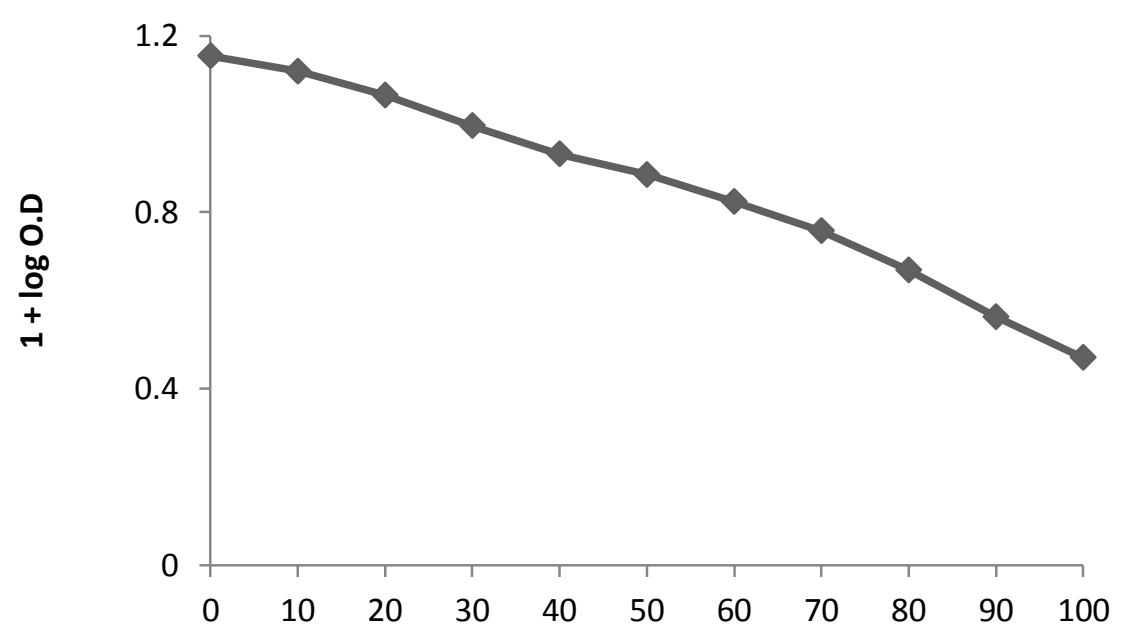

Time (min.)

Fig-4 Kinetic study 


\section{CONCLUSION}

Immobilized Dowex-11 has low cost, high catalytic activity and extended potential for reuse. It can efficiently catalyze the decolorization of Azo dye Direct yellow-9 in presence of light. Therefore this technology has very good potential of organic molecule transformation from complex molecule to simpler molecules. Azo dye which pollutes large part of textile effluent can transform in colorless and nontoxic compounds so this catalyst may applicable for industrial purpose for improvement in quality of waste water of textile industries and many others.

\section{ACKNOWLEDGEMENTS}

The Head of the department is gratefully acknowledged for providing necessary facilities.

\section{REFERENCES}

[1]. Tripathi A. K., Singh R. C., 1984. Indian Journal of Environmental Protection 16, 748.

[2]. "Pollution - Definition from the Merriam-Webster Online Dictionary". Merriam-webster.com. 2010-0813.Retrieved 2010-08-26.

[3]. Wang C., Yediler A., Lienert D., Wang Z., Kettrup A., 2002. Chemosphere 46(2), 339-344.

[4]. Dae-Hee A., Won-Seok C., Tai-II Y.,1999. Process Biochemistry 34, 429-439.

[5]. Shu H. Y., Huang C. R.,1995. Chemosphere 31(8), 3813-3825.

[6]. Konstantinou I. K., Albanis A., 2004. TiO2-assisted photocatalytic degradation of azo dyes in aqueous solution: kinetic and mechanistic investigations: A review. Applied Catalysis B: Environmental 49, 1-14.

[7]. Himakshi, Neelakshi, Meena R. C, 2013. MBIR Dowex-11 Assisted Photocatalytic Degradation of Azo Dyes: A Review. Scientific Reviews and Chemical Communications 3(4), 181-189.

[8]. Meena R. C., Verma H., Disha, 2013. Studies on Photocatalytic Degradation of Azo Dye Acid Red-18 (PONCEAU 4R) using Methylene Blue Immobilized Resin Dowex-11. International Research Journal of Environment Sciences. 2(12), 35-41.

[9]. Verma H., Verma N., Meena R. C., 2014. Effect of Operational Parameters on Photocatalytic Transformation of Azo Dye Sunset Yellow in Water. International Journal of Chemistry and Pharmaceutical Sciences, 2(3), 658-665.

[10]. Verma H., Meena R. C., 2014. A Comparative Study on color removal rate of water containing the Azo Dye [Acid Red 14, Acid Yellow 17 and Sunset Yellow FCF] using Advanced Oxidation Process in the presence of MBIRD-11 as a catalyst. International Journal of Pure and Applied Research in Engineering and Technology 2 (7), 917.

[11]. Verma H., Meena R. C., 2014. Photocatalytic Transformation of Acid Red- 8 by Heterogeneous Photocatalysis using MBIR Dowex-11 as photocatalyst in Aqueous Solution. International Journal of Chemistry and Pharmaceutical Sciences 2(4), 745-751.
[12]. Verma H., Meena R. C., 2014. Solar Radiation Assisted Photocatalytic Transformation of Azo Dye. Journal of Environmental Science, Computer Science and Engineering \& Technology 3(3), 1136-1144.

[13]. Heaton F. W., 1960. Determination of magnesium by the Titan yellow and ammonium phosphate methods. Journal of Clinical Pathology 13, 358-360.

[14]. Pallavicini C., 1962. Determination of magnesium in tissue by the Titan yellow method in the presence of silver and mercury. Proceedings of the Society for Experimental Biology and Medicine 110, 235-237.

[15]. Cornfield A. H., Pollard A. G., 1950. Use of titan yellow for the determination of magnesium in plant material. Journal of the Science of Food and Agriculture 1, 357-358.

[16]. Meyrowitz R., 1964. The direct spectro photometric micro determi- nation of high - level magnesium in silicate minerals. American Mineralogist 49, 769-777.

[17]. Hong-Wen G., Peng-Fei Z., 1994. $\beta$-correction spectro photometric determination of beryllium in waste water with titan yellow. Analytical Proceedings including Analytical Communications 31(3), 85-87.

[18]. Mingxia W., Zhongfang L., Xiaoli H., Shaopu L., Ling K., 2006. Study on the interaction of amino glycoside antibiotics with Titan Yellow by spectro photometric method and their analytical applications. Frontiers of Chemistry in China 2, 170-173.

[19]. Wei X., Liu Z., Liu S., 2006. Resonance Rayleigh scattering spectra of tetracycline antibiotic- $\mathrm{Cu}$ (II) -titan yellow systems and their applications in analytical chemistry. Analytical and Bioanalytical Chemistry 385(6), 1039-1044.

\section{BIOGRAPHIES}

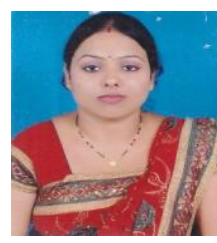

HIMAKSHI VERMA, I am complete my post graduation in 2010. After this continuously work as researcher and since January 2013pursuing Ph.D. in field of photochemistry. I am member of PRL \& RSH and author and coauthor of 10 papers which published in very reputed journals.

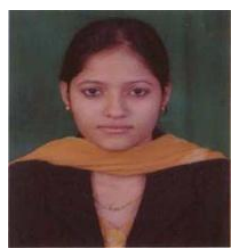

NEELAKSHI VERMA, She is pursuing $\mathrm{Ph} . \mathrm{D}$. in field of defluoridation using photochemistry. She has published 10 papers in reputed journal. She is CSIRNET-JRF with 26 AIR and presently availing SRF. She's been a member of PRL, RSH, ISRAPS, ICS, ISST.

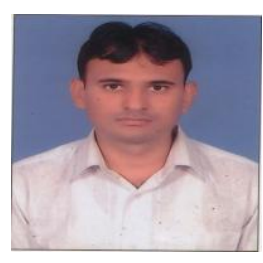

SHIV RAM SAINI, He doing Ph.D in field of photochemistry. $\mathrm{He}$ is CSIR NET JRF. 
Dr. R. C. MEENA, He has worked in field of photochemistry. His recent position is Associate Professor in Department of Chemistry, Jai Narian Vyas University, Jodhpur, Rajasthan. More than 15 students at Ph.D. level have been working under advisor ship of Dr. Meena. He has authored and coauthored over 60 paper publication. 